\title{
Patient experience of whole body diffusion weighted magnetic resonance imaging (WB-MRI) for staging myeloma
}

\author{
S Otero*, M Kaiser, C Pawlyn, S Giles, E Scurr, C Messiou \\ From International Cancer Imaging Society Meeting and 15th Annual Teaching Course (ICIS 2015) \\ London, UK. 5-7 October 2015
}

\begin{abstract}
Aim
WB-MRI provides a fast, highly sensitive assessment of disease burden in myeloma. The 2015 International Myeloma Working Group consensus statement recommends WB-MRI for staging asymptomatic myeloma and for workup of solitary bone plasmacytoma. The technique is noisy, employs whole body surface coils, and takes longer than a standard MRI spine. We assessed patient experience of WB-MRI and identified causes for incomplete examinations.
\end{abstract}

\section{Methods}

36 consecutive patients undergoing WB-MRI for myeloma (whole body DWI and Dixon, fast T1w and T2w spine) were included. Patients anonymously completed a tenquestion survey about their experience. The reporting radiologist recorded technical details and radiological findings.

\section{Results}

WB-MRI was well tolerated in most patients. $89 \%$ completed the protocol; kyphosis and claustrophobia were causes of incomplete studies. 85\% found the scan 'not at all unpleasant' or 'not too unpleasant'.

96\% were satisfied with the quality of information provided to them prior to the examination. $93 \%$ had had a previous MRI and $86 \%$ were not worried about having WB-MRI. 93\% would have a repeat study.

Average scan length was 48 minutes. Two-thirds of patients found this acceptable. $18 \%$ of patients cited claustrophobia as the reason for finding the examination too long. $44 \%$ of patients had chronic vertebral fractures, but

* Correspondence: oterosofia@hotmail.com

The Royal Marsden Hospital (Surrey), Sutton, Surrey, SM2 5PT, UK this did not correlate with the level of discomfort experienced. Half of scans were positive for active disease.

\section{Conclusions}

Patients report a high level of satisfaction with WB-MRI at our institution. The protocol was completed in almost all patients, and most stated they would have a repeat study.

Published: 2 October 2015

doi:10.1186/1470-7330-15-S1-P13

Cite this article as: Otero et al:: Patient experience of whole body diffusion weighted magnetic resonance imaging (WB-MRI) for staging myeloma. Cancer Imaging 2015 15(Suppl 1):P13.
Submit your next manuscript to BioMed Central and take full advantage of:

- Convenient online submission

- Thorough peer review

- No space constraints or color figure charges

- Immediate publication on acceptance

- Inclusion in PubMed, CAS, Scopus and Google Scholar

- Research which is freely available for redistribution

Submit your manuscript at www.biomedcentral.com/submit
() Biomed Central 